\title{
Estimation of Elemental Distributions by Combining Artificial Neural Network and Inverse Distance Weighted (IDW) Based on Lithogeochemical Data in Kahang Porphry Deposit, Central Iran
}

\author{
Reza Karami ${ }^{1, *}$, Peyman Afzal ${ }^{1,2}$ \\ ${ }^{1}$ Department of Mining Engineering, South Tehran Branch, Islamic Azad University, Tehran, Iran \\ ${ }^{2}$ Camborne School of Mines, University of Exeter, Penryn, UK \\ *Corresponding Author: Reza.Karami@gmail.com
}

Copyright (C)2015 Horizon Research Publishing All rights reserved.

\begin{abstract}
Estimation of elemental distribution based on geochemical data is important for determination of elemental prospects in studied areas. The main aim of this study is to estimate $\mathrm{Cu}, \mathrm{Mo}, \mathrm{Au}$ and $\mathrm{Ag}$ with respect to lithogeochemical data in Kahang porphyry deposit, Central Iran, using combination of Inverse Distance Weighted (IDW) and Artificial Neural Network (ANN). The results obtained by the combination methods show that the proper elemental anomalies are associated with geological particulars including lithological units, alteration zones and faults. Moreover, correlation between raw data and the results reveals that the combination method can be applicable for interpretation of elemental distributions.
\end{abstract}

Keywords Grade Estimation, Artificial Neural Network, Inverse Distance Weighted (IDW), Kahang Porphyry Deposit

\section{Introduction}

Geostatistical methods for elemental concentrations estimation is essential regarding surface and subsurface data such as geochemical exploration $[1,2]$. Using statistical and interpolation methods will lead to determining the geochemical anomalies for further suggested detailed exploration. Since 1930, research on the geochemical methods for exploration of ore deposits have been carried out and severally developed $[3,4,5,6,7,8]$. An important aspect of geochemical exploration is the estimation of two- dimensional (2D) ore grade distribution in a studied area. Accordingly, several methods were proposed consisting of linear and non-linear kriging methods, inverse distance weighted (IDW), interpolating polynomials, splines, power and Fourier series fitting $[9,10,11,12]$. Determination of elemental distributions due to stream sediments and lithogeochemical data using IDW estimation technique is a conventional method for geochemical exploration which is one of the most current moving average interpolation techniques based on the assumption considering values of neighboring observations in connection with distances between known and unknown points [13]. The IDW typically allocates more weight to closest points rather than distant points [14]. The IDW method directly utilizes coordinate information of sample points to accomplish interpolation [15]. However, this method is not absolute and naturally includes weaknesses and strengths. According to the development of geosciences-based researches, the IDW method in contribution with other advanced methods like Artificial Neural Network (ANN) is useful. The ANN is a kind of predictor which is non-linear modeling and it figures out complicate patterns. As a result, it can improve performance in combination with above-noted geostatistical methods [16]. Back Propagation-Artificial Neural Network (BP-ANN) is one of the most common versions of ANN which is widely utilized in geosciences such as remote sensing and geochemical exploration for hydrocarbons [17] and hydrogeology [18]. Advantages of ANN include independent of physics-based algorithm to build up a model; therefore, the approach is faster and more flexible than physics-based modeling approaches in most cases. Furthermore, ANN can manage nonlinear relationship between studied attributes and expertise user experiences may be comprised easily into the model structure $[19,20]$. Overestimate and underestimate appear due to the memory effect. High number of weight and freedom degree cause huge mistake in calculation and weak prediction. The more input elements in order to learn the network, the better validation and also the less variance in test and Root Mean Square Error (RMSE) of result is achieved. This paper aims to prepare a method using IDW to achieve basic data 


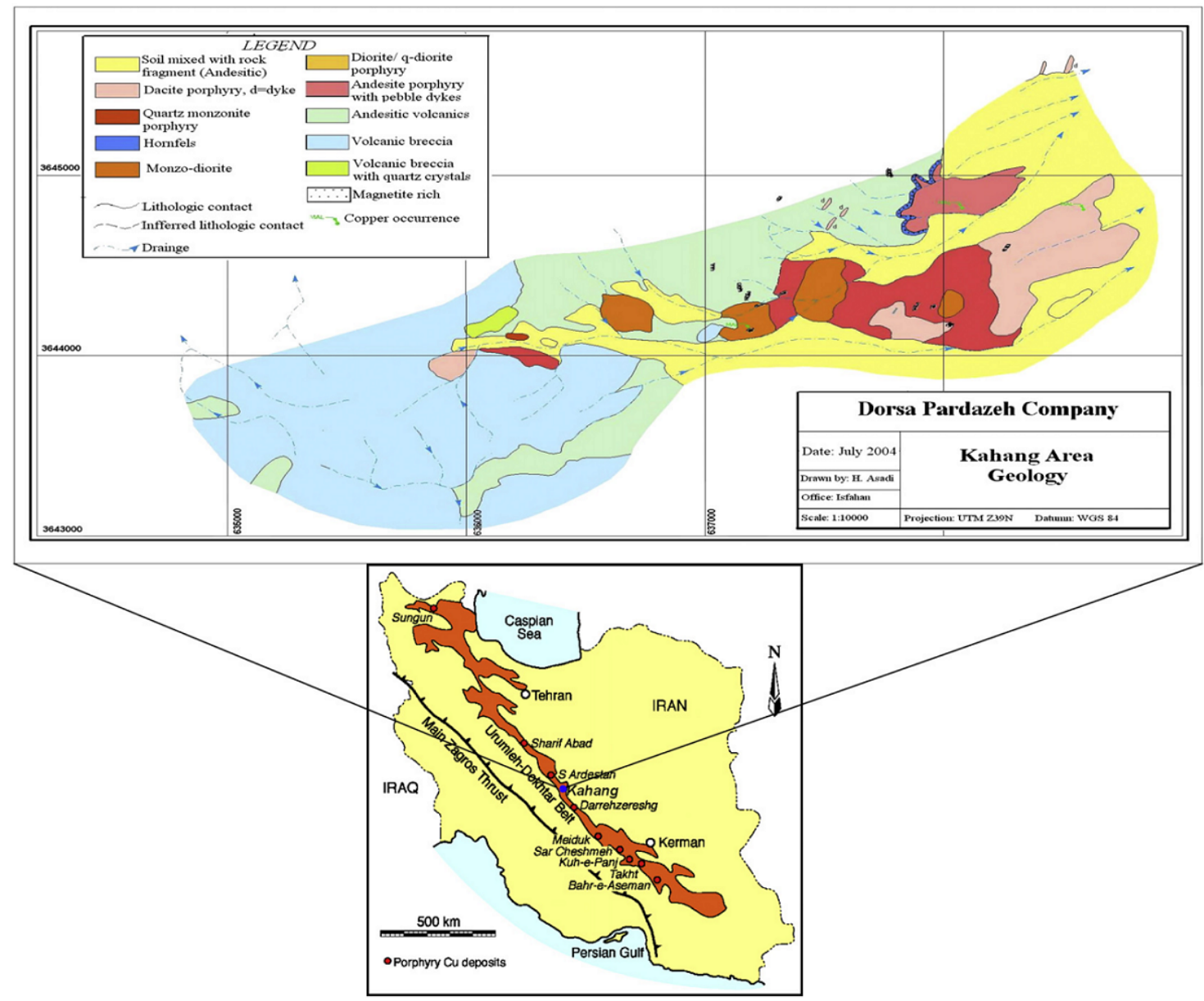

Figure 1. Geology map of the Kahang deposit(scale: 1:10,000) within Urumieh-Dokhtar magmatic belt and the main porphyry deposits in the belt.

leading better process of neural network without being affected limited number of input elements. The outputs are adapted with geological and lithological maps and obtained results of drilling to validate data. Subsequently, data was prepared by the IDW and consequent results with the coordination of each point were transferred to the ANN to in order to outline elemental distributions of $\mathrm{Cu}, \mathrm{Mo}, \mathrm{Au}$ and $\mathrm{Ag}$ in the Kahang porphyry deposit. There is 143 lithogeochemical samples for prospecting of $\mathrm{Cu}, \mathrm{Mo}$ and $\mathrm{Au}$ anomalies due to determination of prospects for detailed exploration. The case study presented here is related to a $\mathrm{Cu}$, Mo, $\mathrm{Ag}$ and $\mathrm{Au}$ grade estimation and it covers the relevant Interpolation techniques. A general discussion is argued whereby the enriched values are related to the relevant structural, lithological and alteration data which explain how the achieved results were derived. Additionally, an emphasis was made on how the main conclusion was obtained. The usage of this procedure and how future issues may be managed using the suggested methods was demonstrated in the present work.

\section{Methodology}

Initially, an IDW-ANN method (combination between IDW and ANN) was proposed entitled and consequently all interpolations were compared together. In this study,
$70 \%$ of the collected samples were used for training of the network. Moreover, $30 \%$ of data were utilized for test and validation purposes.

\section{$2.1 \quad$ IDW}

The Inverse Distance Weighted (IDW) method is commonly used for geochemistry map developing and estimate the value of location between measured points for generation of geochemical maps. The IDW is based on the nearer observed points. IDW has general form as $[21,12]$ :

$$
\hat{z}\left(x_{0}\right)=\frac{\sum_{i=1}^{N} w\left(d_{i}^{-1}\right) z\left(x_{i}\right)}{\sum_{i=1}^{N} w\left(d_{i}^{-1}\right)}
$$

Where $\mathrm{w}$ is the weighting function of the inverse of the distance (di) between the observation at xi and the interpolation point $\mathrm{x} 0$. The IDW method was implemented in MATLAB 2013b software. Cu, Mo, Au and Ag interpolation maps with this method are illustrated in (Figure 2).

\section{$2.2 \quad$ ANN}

Biologists led to human brain function understanding and afterwards mathematicians accomplish to present a mathematical model from a brain neuron. Various kinds of neural networks will be obtained utilizing different combination of mathematical models of neurons and 


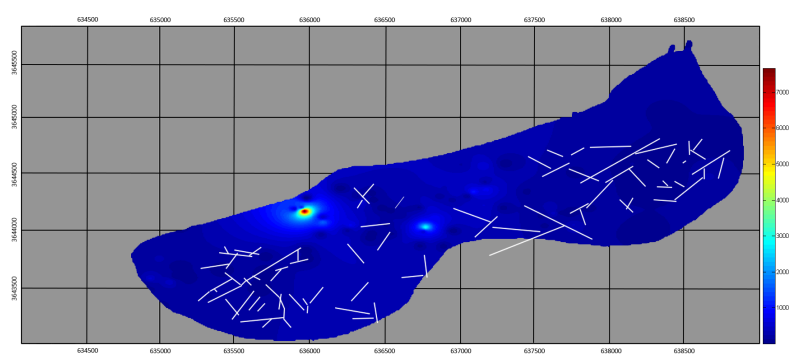

(a) $\mathrm{Cu}$

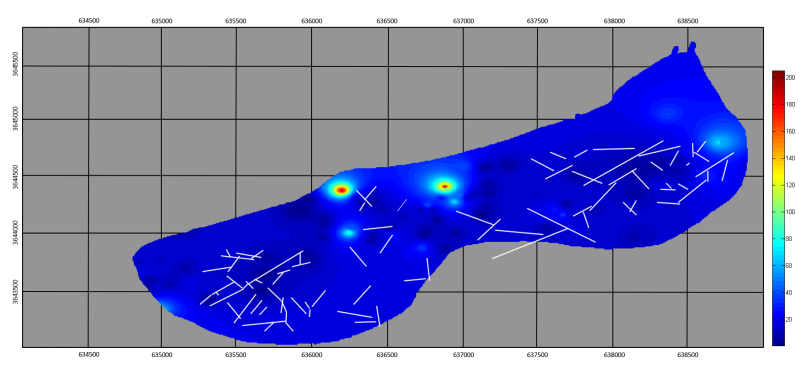

(b) $\mathrm{Mo}$

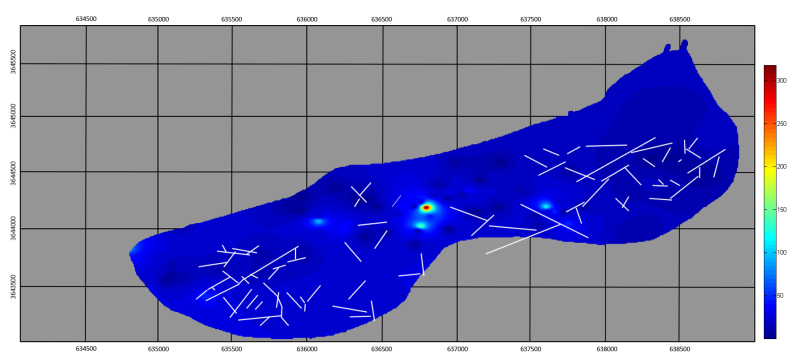

(c) $\mathrm{Au}$

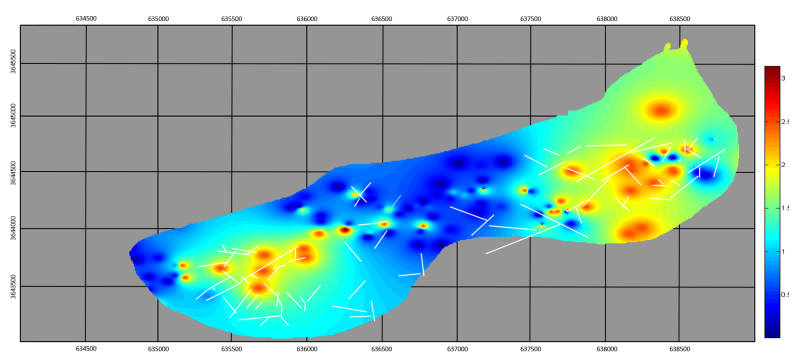

(d) $\mathrm{Ag}$

Figure 2. IDW interpolation for $\mathrm{Cu}, \mathrm{Mo}, \mathrm{Au}$ and $\mathrm{Ag}$ within faults (Light lines)

weighting during learning process which each one is capable of doing special kind of estimation. Multilayer perceptron (MLP), known as the error Back-Propagation (BP) method is a self-organizing, self-teaching and nonlinear model which can be applied in a wide range of problems such as pattern recognition, function approximation, forecasting, time series using computation software packages (e.g., MATLAB ). To run a MLPs, data is fed to the network which represents feed-forward computations to compute the results. The results will be compared with target values and the RMSE is calculated. The RMSE is then back propagated through the MLP utilization of the gradient-descent rule to change the weights and minimize the RMSE. In this kind of ANN, learning starts with a training set of data and uses the BP algorithm to calculate the weights of MLP biases by executing any possible training examples into the network as depicted in (Table2) [22]. The neural network became a proper estimator when input data with specified testifier output is applied and the ANN result shows approximation to that specified output. The number of neurons in the input and output layers corresponds to the expected input and output variables of problem. Network structure depends upon the number of input and output variables and the number of hidden layers and neurons in each one. The hidden layers and their neurons may affect the training efficiency and the prediction accuracy. The number of hidden layer and neurons on each layer in this study has been found practically. Three input neurons are devoted to an input layer; two layers with different numbers of neurons in each one to hidden layers; one output neuron to output layer. The activation functions are non-linear tangent hyperbolic. Moreover, $70 \%$ of raw data has been assigned to train stage and $15 \%$ to validation and $15 \%$ to test. Code wrote in MATLAB 2012 and ANN algorithm has been designed to find correlation coefficient more than $80 \%$ but due to the lake of sufficient data, this goal did not come true and more than $70 \%$ percent correlation coefficient could not be achieved(Figure 3).

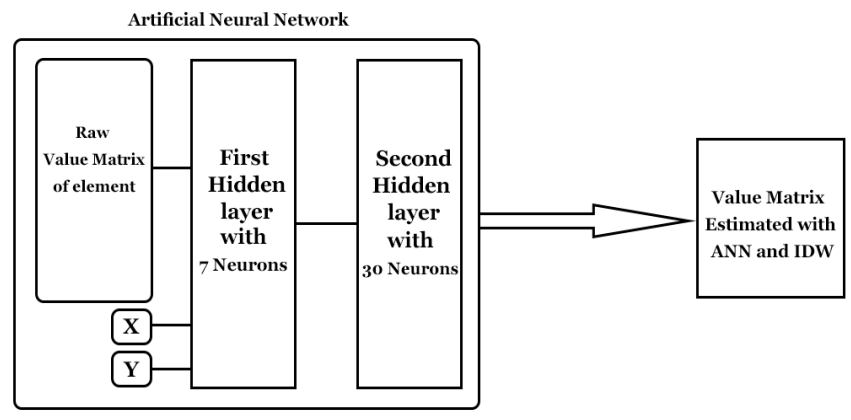

Figure 3. ANN diagram

\subsection{Coordination correlation}

The number of samples used as input data to the neural network is in direct relation with the result of learning, validating and testing procedures. So that, the more samples, the more appropriate analysis from elements distribution will be achieved. In this study, 143 geochemical samples were used in this study which are not acceptable for the start of the study. As a result, the point samples of 22 elements were analyzed and a matrix of $(22+2) * 143$ was achieved from the number of understudy points. Two rows of matrix are devoted the $\mathrm{X}$ and $\mathrm{Y}$ coordination of every point and this is an appropriate data for the start of a neural network learning and testing. The enriched value data of each element with a special distribution pattern was applied to a network and a total distribution was achieved. Distinguishing a special pattern (e.g., $\mathrm{Cu}$ distribution pattern) among others, is the neural network capability.

\subsection{IDW-ANN}

Lack of input data for learning stage and having high RMSE in single form of ANN and on the other hand, the 


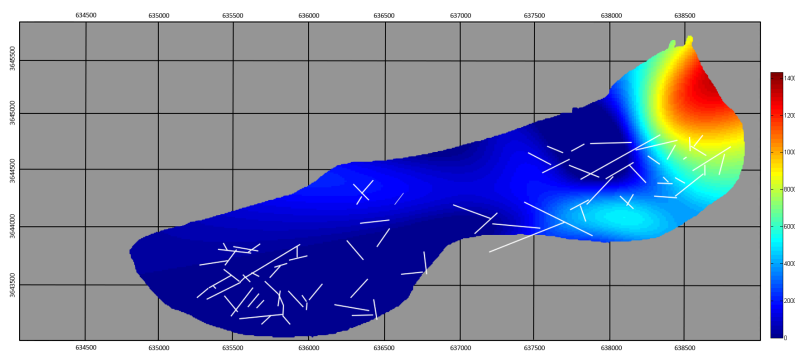

(a) $\mathrm{Cu}$

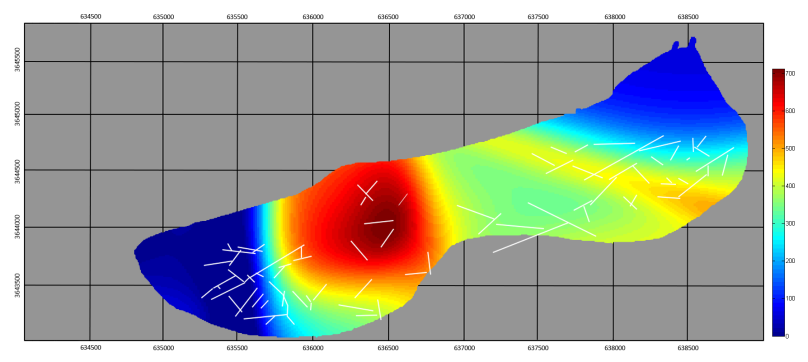

(b) Mo

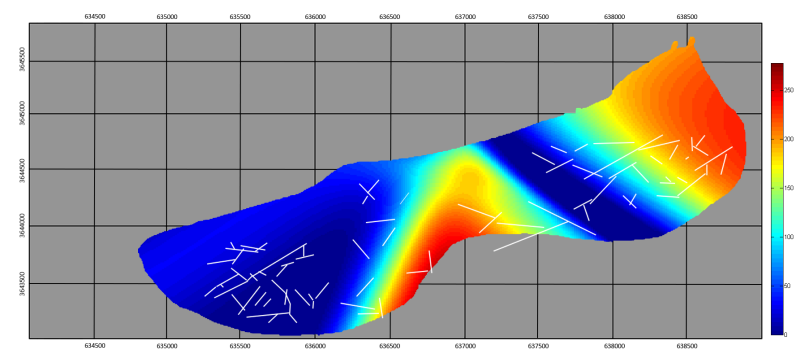

(c) $\mathrm{Au}$

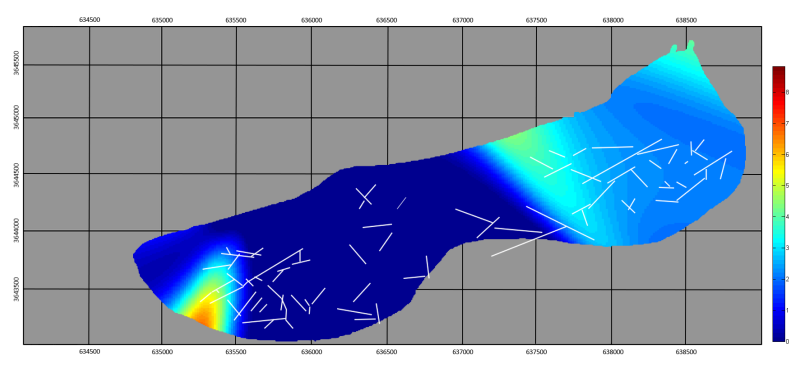

(d) $\mathrm{Ag}$

Figure 4. ANN interpolation for $\mathrm{Cu}, \mathrm{Mo}, \mathrm{Au}$ and $\mathrm{Ag}$ within faults (Light lines)

lack of normal distribution inside the study zone, the IDW-ANN method has been applied. The IDW algorithm was utilized for 22 element with coordinate of 143 point $(\mathrm{X}, \mathrm{Y})$ and the result of each element was stored in a matrix with dimension corresponding to the studied area. Furthermore, the matrix and the coordination of each point were given to the neural network as the input data. The applied flowchart of IDW-ANN steps is shown in (Figure 5).

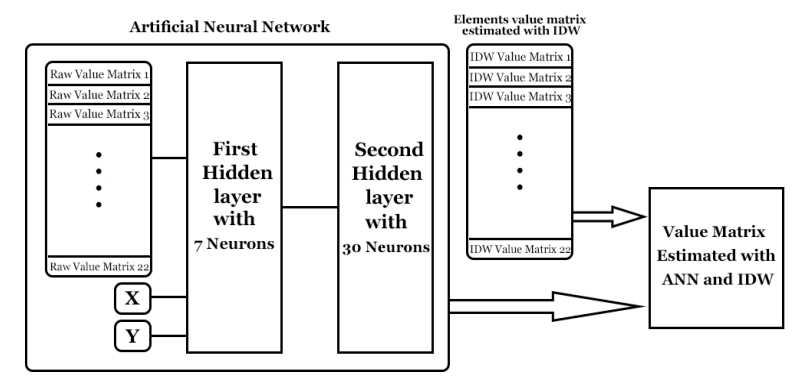

Figure 5. IDW ANN diagram

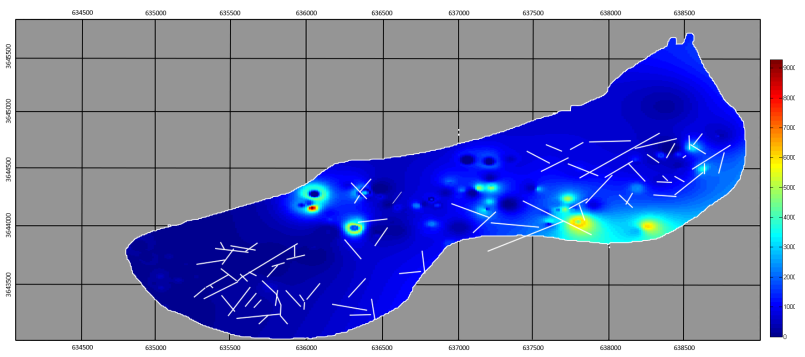

(a) $\mathrm{Cu}$

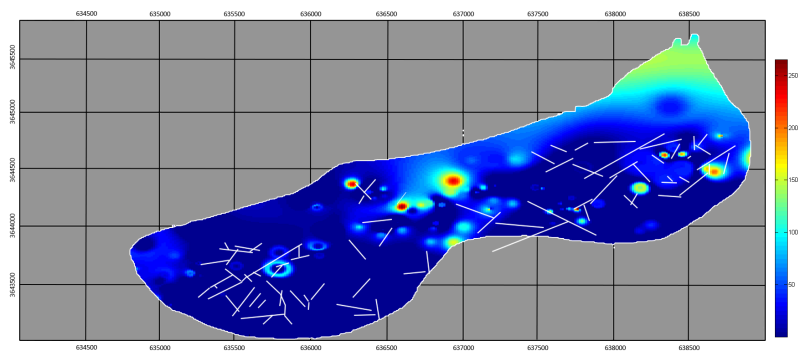

(b) Mo

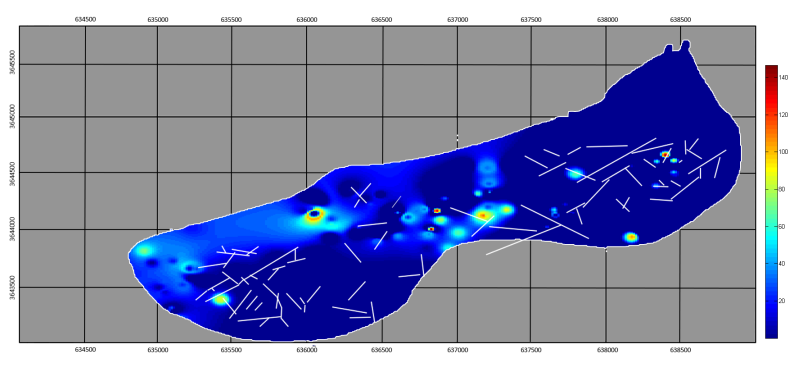

(c) $\mathrm{Au}$

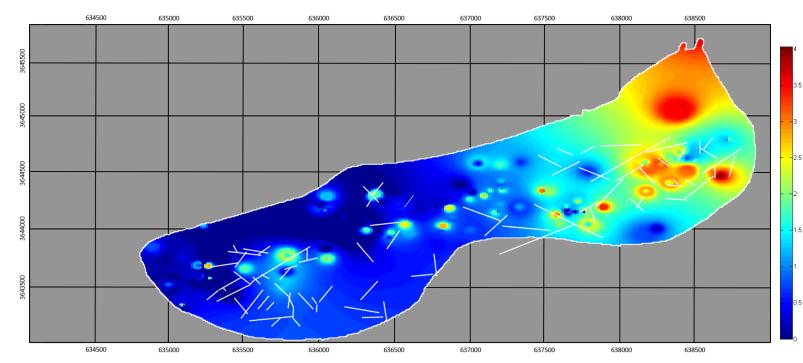

(d) $\mathrm{Ag}$

Figure 6. IDW-ANN interpolation for $\mathrm{Cu}, \mathrm{Mo}, \mathrm{Au}$ and $\mathrm{Ag}$ within faults (Light lines) 
Table 1. IDW method statistic

\begin{tabular}{lrrrr}
\hline \hline Elements & \multicolumn{1}{c}{$C u$} & \multicolumn{1}{c}{$M o$} & \multicolumn{1}{c}{$A u$} & \multicolumn{1}{c}{$A g$} \\
\hline Variance & 8125.21 & 188.78 & 50.69 & 1.29 \\
Mean & 190.54 & 22.93 & 15.34 & 1.17 \\
Median & 152.37 & 138.01 & 3.34 & 1.02 \\
SD & 90.14 & 13.74 & 7.12 & 1.14 \\
Min value & 7.05 & 0.68 & 0.09 & 0.01 \\
Max value & 7668.8 & 205.21 & 318.03 & 3.14 \\
\hline
\end{tabular}

Table 2. ANN method statistic

\begin{tabular}{lrrrr}
\hline \hline Elements & \multicolumn{1}{c}{$C u$} & \multicolumn{1}{c}{$M o$} & \multicolumn{1}{c}{$A u$} & \multicolumn{1}{c}{$A g$} \\
\hline Variance & 19421.20 & 3108.06 & 1812.20 & 2.07 \\
Mean & 305.33 & 118.75 & 65.95 & 1.46 \\
Median & 268.59 & 49.34 & 97.93 & 1.67 \\
SD & 139.36 & 55.81 & 42.57 & 1.44 \\
Max value & 5022.3 & 713.1816 & 277.8974 & 8.8366 \\
\hline
\end{tabular}

Table 3. IDW-ANN method statistic

\begin{tabular}{lrrrc}
\hline \hline Elements & \multicolumn{1}{c}{$C u$} & \multicolumn{1}{c}{$M o$} & \multicolumn{1}{c}{$A u$} & \multicolumn{1}{c}{$A g$} \\
\hline Variance & 4598.80 & 228.31 & 35.04 & 0.96 \\
Mean & 408.11 & 17.95 & 12.12 & 0.83 \\
Median & 60.46 & 25.98 & 18.21 & 0.67 \\
SD & 69.97 & 15.11 & 5.92 & 0.98 \\
MSE & 268.63 & 150.55 & 679.64 & 26.93 \\
RMSE & 16.39 & 12.27 & 26.07 & 5.19 \\
Max value & 5022.3 & 713.1816 & 277.8974 & 8.8366 \\
\hline
\end{tabular}

\section{Kahang Cu- Mo porphyry de- posit}

The Kahang porphyry deposit is located in $73 \mathrm{~km}$ NE of Isfahan, Central Iran. This area is in UrumiehDokhtar magmatic belt and it is known as a significant $\mathrm{Cu}, \mathrm{Mo}$ and $\mathrm{Au}$ deposit, which contains more than 100 million tons of sulfide ore with an average grade of $0.6 \% \mathrm{Cu}$ and $70 \mathrm{ppm} \mathrm{Mo} \mathrm{[23].} \mathrm{This} \mathrm{deposit} \mathrm{occurred}$ within the Cenozoic, one of the subdivisions of Zagros orogenies[24, 25].This belt outstretch for some $2000 \mathrm{~km}$ from NW to SE Iran. Many of the Iranian porphyry Cu deposits such as Sungun, Sarcheshmeh, and located are situated in this belt [26]. The Kahang mineralized area includes a $\mathrm{Cu}$ Mo porphyry deposit and was discovered in 2005 by remote sensing imaging techniques, geophysical methods and geochemical studies [27]. Geological, geophysical, geochemical, alteration patterns as well as drilling data show that there could be a large $\mathrm{Cu}$ porphyry deposit as Kahang [27, 28, 29]. Target zones are mainly comprised of Eocene volcano-pyroclastic rocks which intruded by Oligo-Miocene quartz monzonite, monzogranitediorite to diorites (Figure 1). The volcanic rocks, include explosive eruption and ejection of pyroclastic such as tuffs, breccias and lavas. Variation from dacitic to andesiticin composition with porphyry texture exist in the eruption of pyroclastic rock. Emplacement of subvolcanics and intrusive rocks with andesitic, monzonitic, dacitic and dioritic composition, respectively. In western part of the field, various breccias included hydrothermal, silisic and tectonic breccias were occurred and there is an epithermal system which hosts gold mineralization in silisic veins and veinlets in high level parts of subvolcanic bodies [28]. Two fault systems trending NE-SW and NW-SE locally are the main structural features in this area. The principal alteration zones including potassic, phyllic, argillic and propylitic are ac-
Table 4. Data of sample point

\begin{tabular}{lclll}
\hline \hline Elements & $C u$ & $M o$ & $A u$ & $A g$ \\
\hline Variance & 103.8667 & 213.2000 & 387.2000 & 324.6667 \\
Mean & 105.6667 & 101 & 100 & 97.6667 \\
Median & 103.5 & 102.5 & 102.5 & 100 \\
STD & 10.1915 & 14.6014 & 19.6674 & 18.0185 \\
Min value & 7 & 0.6 & 0 & 1 \\
Max value & 7740 & 219 & 320 & 3.16 \\
\hline
\end{tabular}

companied by the vein to veinlets of quartz, quartzmagnetite and Fe-hydroxides fillings. Mineralization has arised within the brecciated and intrusive bodies and their surrounding host rocks. The ore minerals, including chalcocite, covelite, chalcopyrite, pyrite, malachite, magnetite, hematite, jarosite, goethite, chalcantite, are occurred with intense zones of quartz stockwork, hydrothermal-tourmaline breccia, quartz-sericite and locally potassic alteration. The presence of $\mathrm{CuSO} 4$ in this deposit which is rare in Iranian $\mathrm{Cu}$ porphyry systems, may be interpreted as oxidizing conditions.

\section{Result and Discussion}

The studied area was gridded and divided into $35 \mathrm{~m}$ $20 \mathrm{~m}$ cells. After the checking of 143 geochemical samples and applying them in 5 estimator algorithms, the results were compared. The highest value of raw data contributed in the test were $7740 \mathrm{ppm}, 219 \mathrm{ppm}, 320 \mathrm{ppb}$ and $3.16 \mathrm{ppm}$ for $\mathrm{Cu}, \mathrm{Mo}, \mathrm{Au}$ and $\mathrm{Ag}$ respectively (Table 4). In comparison with ANN method, the IDW method showed less variance for these elements so it is important to know using ANN method presents smoother output results compared with IDW method. The ANN does not demonstrate a proper estimation and shows high amount of overestimation and underestimation. Generally, it is the non-sufficient information for the neural network during the learning which causes unwell generalizing. The results derived via ANN indicate higher variance than IDW but less estimation instead (Tables $1,2)$. The IDW was carried out a separate zone in each estimation and has shown actually a better result. The mean value of IDW estimation for $\mathrm{Cu}$ is reasonable in comparison with ANN (Figure 2). Generally, the results obtained by IDW has presented a better output in $\mathrm{Cu}$ estimation. Overestimation also can be observed for Mo in ANN. The IDW determines minor halo and in ANN it shows overestimation. In spite of IDW, ANN shows high difference by presenting the estimation value of 713 ppm. Underestimation is a little regardable by IDW and not acceptable by ANN (Figure 4). Additionally, the result obtained by IDW estimation for Au was better than ANN such as $\mathrm{Cu}$ and Mo. After reviewing the pervious methods, an IDWANN method was proposed and established. The most important reason of using this method is the high generalization of neural network in estimating with high validation. Each method was tested with $22+2$ set of data from 143 geochemical sample points which means they obtain 12 time better learning of neural network than the estimation method with 2 coordinates elements and also they have reasonable performance (Table 3). MSE and RMSE in estimating of $\mathrm{Cu}$ revealed the values equal to 38005 and 194.94 for MSE and RMSE, 


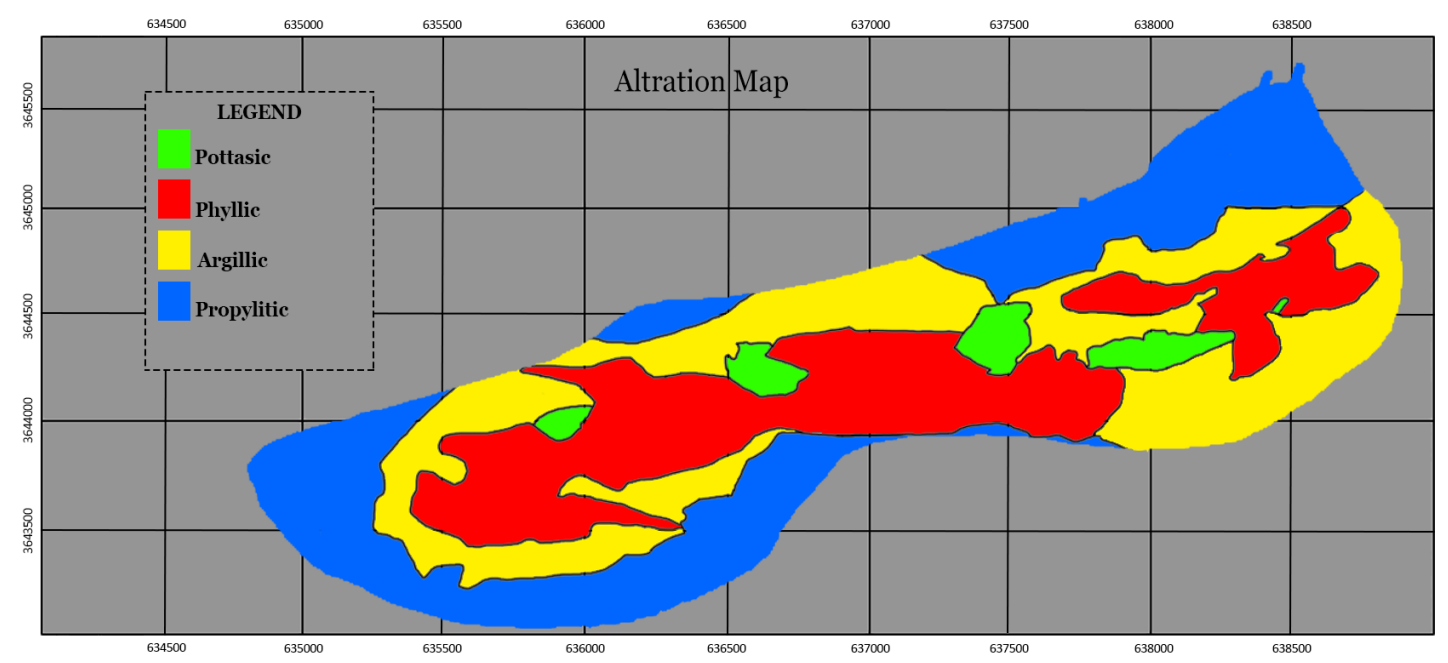

Figure 7. Alteration map of the Kahang deposit

respectively. Furthermore, the IDW has shown a better performance compared with ANN (in pervious part) which concluded that the neural network has got the effect and the IDW-ANN presents more reliable results. The $\mathrm{Cu}$ distribution model derived via the IDW-ANN method exist in the western and eastern parts of the area. Moreover, the Mo enriched parts occurred in the central part of the area based on the method. The high differentiation in estimation of $\mathrm{Ag}$ is even more observable (Table 3). The elemental maps were generated due to the IDW-ANN method depicted in (Figure 6).

\section{Correlation between the re- sults derived via IDW-ANN and geological particulars}

To ensure the validity of the obtained results from IDW-ANN, the outputs were correlated to the geological characteristics including lithological, faults and alteration maps (Figures 1and 7). The enriched parts of $\mathrm{Cu}$, $\mathrm{Au}, \mathrm{Mo}$ and $\mathrm{Ag}$ have close relation with faults. However, the main parts of elemental accumulations have a direct relationship with faults intersections. Comparison between lithological units and estimation results derived via IDW-ANN revealed that the quartz monzonite and andesitic monzodiorite have high amounts of $\mathrm{Cu}$ mineralization and this is perceptible in the presented maps by IDW-ANN (Table 3). Additionally, main enriched parts of $\mathrm{Au}$ and $\mathrm{Ag}$ are associated with faults and breccias in the western part of the deposit which have high amounts of spaces for mineralization. However, these elemental enrichments are associated with silisic veins and veinlets. The high values of estimated $\mathrm{Cu}$ by IDW-ANN method are associated with potassic and phyllic alteration zones in the central and eastern parts of the area. The Au and $\mathrm{Ag}$ high values which occur in the western and central parts of the area associated with argillic alteration Fig 7. The $\mathrm{Cu}$ anomaly with $5000 \mathrm{ppm}$ is present in potassic alteration.

\section{Conclusion}

Results obtained by the IDW-ANN estimation method showed a good correlation with geological particulars. This method can be used for interpolation of geochemical data. The complication of elemental distribution in the studied area has no impressive effect on the methods preference and also the obtained results validity depend on the neural network generalization and the input data pattern to the network. IDW confronted a few underestimation results but the IDW-ANN method have decreased the errors to the least and presented an appropriate estimation in abnormal distribution of the elements. Coordination correlation in presenting input data was applied for neural network utilization. Consequently, for increasing input data amount and improving neural network learning results, the obtained geochemical analysis data of a point and the coordination of the same point were used and the test results were developed. Monzo-granite-diorite penetration is in close relation with $\mathrm{Cu}-\mathrm{Au}$ enrichment in the central part of the deposit. Furthermore, the silicic veins and breccias have an important role in the western part and monzonite and breccias units have been formed simultaneously with $\mathrm{Au}$ enriched part in the western part of the area. The highest enrichment occurs in fault intersection at the western part of the Kahang deposit. Various kind of breccias can be found as host in the Kahang deposit and the reason is the primary appropriate porosity for saturated fluids involvement. The argillic and phyllic alteration are related to the $\mathrm{Cu}, \mathrm{Mo}, \mathrm{Au}$ and $\mathrm{Ag}$ mineralization in the Kahang zone. The potassic alteration is relevant to the $\mathrm{Cu}-\mathrm{Au}$ enriched parts in the central part of the deposit. Phyllic alteration is related to the $\mathrm{Cu}-\mathrm{Mo}$ anomalies in the western part. Moreover, the argillic alteration is in close relation with $\mathrm{Mo}, \mathrm{Au}$ and $\mathrm{Ag}$ anomalies in the western part of the studied area.

\section{REFERENCES}

[1] Omid Asghari and NasserMadani Esfahani. Erratum to: A new approach for the geological risk evaluation of coal resources through a geostatistical simulation. Arabian Journal of Geosciences, 7(2):839-839, 2014. 
[2] Shahab Shahbeik, Peyman Afzal, Parviz Moarefvand, and Mania Qumarsy. Comparison between ordinary kriging (ok) and inverse distance weighted (idw) based on estimation error. case study: Dardevey iron ore deposit, ne iran. Arabian Journal of Geosciences, 7(9):3693-3704, 2014.

[3] E.V. Baranov. Endogenetic Haloes Associated with Massive Sulphide Deposits, page 336. Nedra Publishing house, 1987.

[4] A. A. Beus and S.V. Grigorian. Geochemical exploration methods for mineral deposits, 1977. Translation of Geokhimicheskie metody poiskov i razvedki mestorozhdenii tverdykh poleznykh iskopaemykh.

[5] Alexander Evgenievich Fresman. Geochemical and Mineralogical Methods of Prospecting for Mineral Deposits., page 350. 1939.

[6] A.P. Solovov. Geochemical Prospecting for Mineral Deposits, page 288. (Kuznetsov, V.V.,Trans.)(Engl. Ed.). Mir, Moscow., 1987.

[7] A.P. Solovov. Handbook on Geochemical Prospecting for Useful Minerals, page 336. Nedra Publishing house, Moscow., 1990.

[8] Mansour Ziaii, Ali A. Pouyan, and Mahdi Ziaei. Neurofuzzy modelling in mining geochemistry: Identification of geochemical anomalies. Journal of Geochemical Exploration, 100(1):25 - 36, 2009.

[9] Richard Franke. Scattered data interpolation: tests of some methods. Math Comput, 38:181 - 200, 1982.

[10] NS Lam. Spatial interpolation methods: a review.

[11] Noel A.C. Cressie. Statistics for spatial data, page 900. Wiley, New York, 1993.

[12] Dale Zimmerman, Claire Pavlik, Amy Ruggles, and Marc P. Armstrong. An experimental comparison of ordinary and universal kriging and inverse distance weighting. Mathematical Geology, 31(4):375 - 390, 1999.

[13] Renguang Zuo. Exploring the effects of cell size in geochemical mapping. Journal of Geochemical Exploration, 112(0):357 - 367, 2012.

[14] Andrew a. Herstrom William E. Hogsett David T. Tingey Donald L. Phillips, E. Henry lee. Use of auxiliary data for spatial interpolation of ozone exposure in southeastern forests. Environmetrics., pages 43-61, 1997.

[15] Jeremy E Diem and Andrew C Comrie. Predictive mapping of air pollution involving sparse spatial observations. Environmental Pollution, 119(1):99 - 117, 2002.

[16] M.W Gardner and S.R Dorling. Artificial neural networks (the multilayer perceptron)a review of applications in the atmospheric sciences. Atmospheric Environment, 32(1415):2627 - 2636, 1998.

[17] Guoping Bai Liuping Zhang. Application of the artificial neural network to multivariate anomalyrecognition in geochemical exploration for hydrocarbons. Geochemistry, Exploration, Environment, Analysis, 2:75$82,2002$.
[18] B. Dixon. Applicability of neuro-fuzzy techniques in predicting ground-water vulnerability: a gis-based sensitivity analysis. Journal of Hydrology, 309(14):17 - 38, 2005.

[19] Qing Zhang and Stephen J Stanley. Forecasting rawwater quality parameters for the north saskatchewan river by neural network modeling. Water Research, 31(9):2340 - 2350, 1997.

[20] Fi-John Chang, Li shan Kao, Yi-Ming Kuo, and ChenWuing Liu. Artificial neural networks for estimating regional arsenic concentrations in a blackfoot disease area in taiwan. Journal of Hydrology, 388(12):65 - 76, 2010.

[21] R.A. Daro and S.C. JosLuis. Performance of geostatistical interpolation methods for modeling sampled data with non-stationary mean. Stochastic Environmental Research and Risk Assessment, 20(6):455-467, 2006.

[22] Jamshidi R. Ghiassian, H. and G. Poorebrahim. Neural networks analysis of silty sand reinforced by carpet wastes. Kuwait Journal of Science and Engineering., 33(1):119-138, 2006.

[23] Peyman Afzal, Younes Fadakar Alghalandis, Parviz Moarefvand, Nematolah Rashidnejad Omran, and Hooshang Asadi Haroni. Application of powerspectrumvolume fractal method for detecting hypogene, supergene enrichment, leached and barren zones in kahang cu porphyry deposit, central iran. Journal of Geochemical Exploration, 112(0):131 - 138, 2012.

[24] Mehdi Alavi. Tectonics of the zagros orogenic belt of iran: new data and interpretations. Tectonophysics, 229(34):211 - 238, 1994.

[25] Manuel Berberian and G. C. P. King. Towards a paleogeography and tectonic evolution of iran. Canadian Journal of Earth Sciences, 18(2):210-265, 1981.

[26] J. Shahabpour. Post-mineral breccia dyke from the sarcheshmeh porphyrycopper deposit, kerman, iran. Exploration and Mining Geology, 3:39-43, 1994.

[27] SH Tabatabaei and H Asadi Haroni. Geochemical characteristics of gor gor cu-mo porphyry system. 25th Iranian symposium on geosciences, Geological survey of Iran, page 60, 2006.

[28] Peyman Afzal, Hamid Harati, Younes Fadakar Alghalandis, and Amir Bijan Yasrebi. Application of spectrumarea fractal model to identify of geochemical anomalies based on soil data in kahang porphyry-type cu deposit, iran. Chemie der Erde - Geochemistry, 73(4):533 $-543,2013$.

[29] Peyman Afzal, Ahmad Khakzad, Parviz Moarefvand, N. Rashidnejad Omran, Bijan Esfandiari, and Younes Fadakar Alghalandis. Geochemical anomaly separation by multifractal modeling in kahang (gor gor) porphyry system, central iran. Journal of Geochemical Exploration, 104(12):34 - 46, 2010. 